Revista de Matemática: Teoría y Aplicaciones 2009 16(1) : 178-187

CIMPA - UCR ISSN: 1409-2433

\title{
SHIPMENT CONSOLIDATION BY TERMINALS AND VEHICLES
}

\author{
Rosa G. González-Ramírez * Ronald G. Askin ${ }^{\dagger} \quad$ Neale R. Smith ${ }^{\ddagger}$ \\ RENÉ VillaLoBos ${ }^{\S}$
}

Recibido/Received: 20 Feb 2008 - Aceptado/Accepted: 6 Nov 2008

\begin{abstract}
This project designs and implements a new module in a logistics analysis tool called "Logistika" that was developed by some graduate students in ASU. Initially, Logistika only had available a "Plant location module", but this work makes an extension to include a new module that is called "Shipments Consolidation module". The objective of the module is to determine the best distribution strategy for products manufactured in Mexico to customers located in US. The tool explores two consolidation strategies: by vehicles and terminals, so as to minimize the transportation and in transit inventory costs incurred. It also considers that it is desired to locate a consolidation center in Mexico for which the best location must be found.
\end{abstract}

Keywords: Consolidation, Location, Cost minimization, routing.

\section{Resumen}

Este proyecto diseña e implementa un nuevo módulo como parte de una herramienta para el análisis de actividades logísticas llamada "Logistika", que fue desarrollada por algunos alumnos de posgrado en la Universidad del Estado de Arizona (ASU). Inicialmente, Logistika solo tenía disponible el "Módulo para la localización de plantas", pero nosotros realizamos una extensión para incluir un nuevo módulo llamado "Módulo para la consolidación de envíos". El objetivo es determinar la mejor estrategia de distribución para productos manufacturados en Mexico hacia clientes ubicados

\footnotetext{
${ }^{*}$ ITESM Campus Monterrey, Tecnológico de Monterrey, Eugenio Garza Sada 2501, 64849 Monterrey, Nuevo León, Mexico. E-Mail: A01050713@itesm.mx.

${ }^{\dagger}$ Arizona State University, Tempe, 85287 Arizona, Estados Unidos. http://www.asu.edu, E-Mail: Ron.Askin@asu.edu

${ }^{\ddagger}$ Misma dirección que R.G. González, E-Mail: nsmith@itesm.mx.

${ }^{\S}$ Misma direcciín que R.G.Askin, E-Mail: Rene.Villalobos@asu.edu.
} 
en Estados Unidos. La herramienta explora dos estrategias de consolidación: por vehículos y por terminales para minimizar los costos de transportación e inventario en tránsito incurridos. También se considera que se desea localizar un centro de consolidación en México para el cual la mejor ubicación debe ser encontrada.

Palabras clave: Consolidación, Localización Minimización de Costos, Ruteo. Mathematics Subject Classification: 90B06

\section{Introduction}

\subsection{Consolidation: Definitions, classification and work done in this field.}

Hall (1987a) defines consolidation as: "The process of combining different items, produced and used at different locations and different times, into single vehicle loads. The aim of consolidation is to take advantage of lower transportation charges, common in the rail, motor carrier and airline industries that come from larger load sizes. Consolidation occurs whenever different items travel in the same load."

According to Min \& Cooper (1990) the concept of freight consolidation was introduced to cope with the frequent and small shipments known as "Less than truckload" (LTL). Successful implementation of consolidation strategies can help to reduce total logistics costs by achieving economies of scale. Hall(1987a) makes the following classification, that is a subset of Brenan (1981)'s classification:

-Inventory consolidation: This is the simplest form of consolidation. It involves storing items that are produced and used at different times, and transporting them in the same load.

- Vehicle consolidation: It involves picking-up and dropping-off items at different origins and destinations (use multiple pick-ups or drop-offs).

-Terminal Consolidation: This is a spatial form of consolidation that brings items from different origins to a single location where they are sorted, loaded into new vehicles, and taken to different destinations.

The best combination of the three different types of consolidation (inventory, vehicle and Terminal), depends on the trade-offs between consolidation benefits and penalties. Hall (1987b) presents some guidelines to decide which consolidation strategy is better in different contexts.

Min \& Cooper (1990) review of the different kinds of consolidation and backhauling strategies in the literature. Pooley \& Stenger (1992) make a comparison between independent LTL(Less than truckload) movements and shipment consolidation. They develop an algorithm to solve the single source shipment consolidation problem. 
180 R. GonzÁlez - R. Askin - N. Smith - R. Villalobos Rev.Mate.Teor.Aplic. (2009) 16(1)

Regarding the consolidation by vehicles, Burns et al. (1985) analyze and compare two distribution strategies: direct shipping and peddling. They define peddling as the strategy that a single vehicle distributes products to several customers. Blumenfeld et al. (1987) develop an algorithm to determine the best shipment strategy for the distribution Network of General Motors. Daganzo (1988) compare in and out vehicles consolidation strategies.

With respect to the consolidation by terminals, Daganzo (1981) study the trade off involved between shipping items directly from the origin to the destination versus shipping through a consolidation center. Blumenfeld et al. (1985) compare direct shipping and consolidation by terminal strategies. Daganzo (1987) examine the structure of many-to-many logistics networks to determine number of terminals and frequency of service. Campbell, (1990) analyze 3 schemes for routing freight shipments via consolidation terminals in a many to many logistics network. Min (1996) proposes a multiphase decomposition heuristic procedure to work on the consolidation terminal location-allocation-routing problem (TLRP).

Finally, regarding inventory consolidation, Roundy (1985) presents the power of two policy for the problem of multiple retailers and one warehouse system. Mahmoud (1992) provides the portfolio quantity effect model. Rosenwein (1997) presents a heuristic for solving the problem of planning and consolidating shipments from a warehouse. Evers \& Beier (1998) explore the operational aspects of inventory consolidation. Wei Shim Lim et al. (2003), study the case of a single warehouse and multiple retailer systems.

\subsection{Facility location}

Location problems arise in many design problems, and they consist on the determination of the better location of a facility involving certain type of distance measure. According to Handler \& Mirchandani, (1979) the most important distance measures are:

-Euclidean metric: the distance between two points is the straight-line distance.

-Rectilinear or Manhattan metric: distance is restricted to take place in directions parallel to the coordinate's axes.

-Shortest distance on a network: this measure results when travel is restricted to take place on a network.

The authors also provide a classification of the facility problems according to their objective function:

-Minisum criterion: The objective is to minimize the average distance to travel. Locations that optimize minisum criteria are referred to as "medians" on networks.

-Minimax criterion: The objective is to minimize the maximum distance traveled. Locations that optimize minimax criteria are referred to as "centers" on an network.

-Multiple criteria: A problem may consist on several criteria to be optimized simultaneously. 


\section{Problem description}

The problem addressed in this work is the definition of the better strategy to distribute products from several suppliers located in Mexico to customers in US., exploring the alternative to reduce transportation costs, by vehicle and terminal consolidation. It is also required to determine the location of the Consolidation Center (CC) in Mexico.

\section{$2.1 \quad$ Assumptions}

1. Each supplier manufactures a single product, however several suppliers can manufacture the same product. To allow multiple products from a supplier, the same supplier can be included the times that are required for the different products done by this supplier.

2. There is no capacity constraint on the suppliers.

3. Demand is known and static over time, considering a single period.

4. Products are transported only by ground and the trip is one way.

5. The location of the suppliers is considered as potential sites to locate the CC, but there can be additional candidates.

6. The function of the CC is just the consolidation of loads.

7. Three trailer types will be considered with their corresponding dimensions and capacity constraints: 40', 48' and 53'.

8. The weight and volume capacity of the vehicles must be estimated according to government regulations in both Countries.

9. Cost function is linear and it includes distribution and in transit inventory costs, border transfer rates, stopping tariffs as well as the consolidation center tariff per pallet.

10. Distances are calculated according to the "great circle formula", which is the shortest path between two points on the spherical surface. This formula led to good approximations, but it can be used any other metric, like the Euclidean or Manhattan metric.

\section{Methodology proposed}

We propose an algorithm that consists on an initialization step and four consecutive stages. A code in Visual Basic.Net was developed and implemented in Logistika tool, [23]. 
182 R. GonzÁlez - R. Askin - N. Smith - R. Villalobos Rev.Mate.Teor.Aplic. (2009) 16(1)

\subsection{Initialization Step}

This step consists on the initial computations required to start the consolidation of the shipments:

1. Compute the Capacity in pallets of the truck according to the 3 types of truck available: 40,48 or 53 .

2. Compute the Capacity in weight of the truck according to the 3 types of truck and the regulations constraints.

3. For each product, determine the products per pallet and the total weight of a pallet. For this matter it is required to define the number of products per layer and if the product is stackable, the number of layers and finally the weight of the pallet which consists on the weight of the total number of products plus the weight of the pallet.

4. Convert demand of each product $l$ of each customer $k$ to pallets and the total weight that corresponds to this demand.

5. Compute the maximum number of pallets per truck according to pallets and weight capacity of the truck. This will be used as capacity constraint in the cases in which the products are not mixed in the truck.

6. Consolidate customers from the same zipcode (five digits). Now instead of customers, they will be referred as "zipcodes":

\subsection{Stage 1: Direct Shipments Strategy}

This stage determines the shipments without using consolidation and computes the total cost incurred. The next stages will consider just the LTL shipments and will use consolidation techniques to save transportation costs over those LTL shipments.

1. Determine the closest (minimum distance) supplier to each zipcode of each product demanded, and the border that allows achieving this minimum distance.

2. For each zipcode $z$ and each product $l$, determine the amount of FTL (Full Truckloads) that can be sent without violating capacity constraints. The remaining shipments will be considered LTL.

3. For each zipcode, compute traveling times and distances between their corresponding suppliers and borders.

4. Compute total cost summing up the LTL and the FTL distribution costs, the in transit inventory costs and the border rates. 


\subsection{Stage 2: Vehicle Consolidation Strategy}

This stage consists on a heuristic procedure to consolidate the LTL shipments from previous stage by vehicles. It is based on a closest insertion and reallocation procedure.

For each supplier $i$ :

1. Consider as the current number of trucks the total number of LTL shipments that supplier $i$ send.

2. Compute the number of trucks that are required to send the total load for the LTL shipments of the supplier $i$ that produces product $l$ considering both pallet and weight constraints.

3. Consider for each supplier $i$, the zip codes $z$ that correspond to each LTL that the supplier send as potential LTL shipments to be consolidated.

4. If the current number of trucks is greater than the number of trucks required to send the total load from supplier $i$, and there exists more than one potential LTL shipments, then combine loads of the LTL shipments until all the shipments are allocated to a route:

(a) Closest Insertion: This phase allocates zipc odes in a route but assigning the whole load.

i. Initially the number of routes is zero and all the potential zip codes are available for all the routes.

ii. Initiate a route, incrementing $r$

iii. Select the potential zip code with smaller load from the LTL shipments that still require to be allocated. Assign this zip code to the route $r$, and delete it from the potential zip codes available for the route. Compute current distance traveled, capacity remaining in the route and cost.

iv. From the potential zip codes for supplier $i$, select the closest zip code $z$ to one of the zip codes that are already allocated to the route $r$.

v. If there is capacity available in the route to add the load of that zip code then:

A. Add the zipcode to the route $r$ and compute current distance traveled, capacity remaining of the route and cost. If no capacity remains, then the tariff must be FTL.

B. Compare the current cost of the route with the cost of sending both shipments independently.

C. If the cost of the route is greater than the cost of sending the load from zipcode $z$ independently, then remove this zipcode from the route $r$, mark it as unavailable for the route $r$ and update the actual capacity remaining. Then go to step 4.(a).iii unless there is no more potential zipcodes to analize for this route. If this is the case, close the route $r$, 
184 R. GonzÁlez - R. Askin - N. Smith - R. Villalobos Rev.Mate.Teor.Aplic. (2009) 16(1)

compute total cost with the corresponding tariff (LTL or FTL) and if there is still more zipcodes to allocate, go to step 4.(a).ii.

D. If the cost of the route is less or equal than the cost of sending the load from zipcode $z$ independently, we left the zipcode in the route $r$. If there is no more capacity left in the route, close it and go to step 4.(a).ii if there is still more zipcodes to allocate.

vi. If there is no capacity available for this load mark the zipcode $z$ as unavailable for the route $r$ and go to step 4.(a).iii unless there is no more potential zipcodes to analize for this route. If this is the case, close the route $r$, compute total cost with the corresponding tariff (LTL or FTL) and if there is still more zipcodes to allocate, go to step 4.(a).ii

(b) Realloaction: This phase improves the current allocations by partition the load of a route and allocating it to the routes with capacity remaining, which implies that the load of a zipcode is sent by different routes.

i. Initially, all the routes with capacity remaining (LTL routes) are available for reallocation.

ii. If the current number of trucks is greater than the number of trucks required to send the total load from supplier $i$, reallocate the load from an available route for reallocation with the minimum load $r$.

iii. From this route, select arbitrarily a zipcode $z$ from the zipcodes that still require to be reallocated. From the routes with positive capacity remaining, select the zipcode $z^{\prime}$ from route $r^{\prime}$ closest to $z$, and allocate the load that is possible in the route $r^{\prime}$.

iv. Compute total distance, time traveled and the cost with the corresponding tariff (if no capacity remain in route $r$ ' the tariff is FTL), and compare the cost of sending the load independently. If it is better to combine the loads, go to step 4.(b).iii unless no other zipcode from route $r$ requires reallocation. Otherwise mark the route $r$ as not available to reallocation and go to step 4.(b).ii

5. Compute the total cost summing up the cost of all the routes.

\subsection{Stage 3: Location of the consolidation center in Mexico}

The procedure is based on the P-Median problem. It is restricted to locate the facility at a vertex (not over a continuous space), which in this case corresponds to the existing suppliers and some additional candidates if there exist.

Given the characteristics of the problem, we consider that there is no more than twenty or thirty candidates to locate the CC, since it is estimated that there are only 60 suppliers in Mexico. Furthermore, it is thought that no more than two $\mathrm{CC}$ are required, and it is more likely that one CC is enough. For these reasons, it is considered a sensitive approach to use an enumeration algorithm that extends the algorithm provided by Hakimi (1970) 
in which the objective function is formed by the fixed and operational costs of the CC, transportation costs and in transit inventory costs.

Procedure:

1. Determine the Demand in the borders that will be the demand points assigning each zipcode to the closest border.

2. Compute Total Cost for each potential site, which includes transfer rates of the border, operational costs of the $\mathrm{CC}$, transportation and in transit holding costs from supplier to the $\mathrm{CC}$ and the $\mathrm{CC}$ to the border

3. Locate the $\mathrm{CC}$ in the site that minimizes such cost.

\subsection{Stage 4: LTL shipments allocation to the consolidation center}

This option assumes that a single CC is located in Mexico and explores two alternatives for the LTL shipments that remains from stage two: send the LTL shipments through the $\mathrm{CC}$ or directly. In the first case, the different products that are sent to each cluster of zipcodes is combined with the aim of sending them as FTL. Given that suppliers produce a single item and have no capacity constraints, the only way to combine items is when several products are demanded in each cluster of zipcodes. Otherwise it is better to send the shipments directly.

Notice that given that we are combining different products to be sent to a zipcode, we need to compute again the capacity of the truck in pallets that takes into account the weight of all the products that will be combined. For this matter we simply take the more restricted capacity for a single product. It is also important to mention that the CC sends directly the products to each zipcode (we do not allow vehicle consolidation from the CC, since we considered that the items will travel a lot of time and the in transit inventory would be too high).

\section{Implementation and conclusions}

We implemented the code in Logistika tool, [24]. We just ran some preliminary examples and results show that consolidation strategies allows the reduction on costs compared with the direct shipment strategy. However it is required to design randomly more instances with different characteristics and perform a complete experimentation.

\section{$5 \quad$ Future research}

As future research we propose to:

1. Extend the algorithm to include capacity constraints in the suppliers. 
186 R. GonzÁlez - R. Askin - N. Smith - R. Villalobos Rev.Mate.Teor.Aplic. (2009) 16(1)

2. Include an additional stage that evaluates 3 different alternatives: -Locate a CC only in Mexico (as it was done in this project). -Locate a CC in USA.

-Locate a CC in both countries.

3. Analyze different modes of construction of the Consolidation Center. One question to answer is whether the costs of the Consolidation Center should be independent of the suppliers as Third Party, or if they should be part of the supplier Consortium.

4. Include inventory considerations.

5. Incorporate in the analysis different modes of transportation such as air.

\section{Ackowledgement}

This research is supported by USAID-TIES and ITESM Campus Monterrey Research Fund CAT025.

\section{References}

[1] Blumenfeld, D.E.; Burns, L.D.; Diltz, J.D.; Daganzo, C.F. (1985) "Analyzing tradeoffs between transportation, inventory and production costs on freight networks", Transportation Research B 19(5): 361-380.

[2] Blumenfeld, D.; Burns, L.; Daganzo, C.F.; Frick, M.; Hall, R. (1987) "Reducing logistics costs at General Motors", Interfaces 17(1): 26-47.

[3] Brennan, J.J. (1981) Models and Analysis of Temporal Consolidation. Ph.D Dissertation, University of California, Los Angeles.

[4] Burns, L.D.; Hall, R.W.; Blumenfeld, D.E.; Daganzo, C.F. (1985) "Distribution strategies that minimize transportation and inventory costs"", Operations Resarch 33(3): 469-490

[5] Campbell, J. (1990) "Freight consolidation and routing with transportation economies of scale", Transportation Research B 24(5): 345-361.

[6] Daganzo, C.F. (1981) "Shipment composition enhancement at a consolidation center", Transportation Research B 22(2): 71-81.

[7] Daganzo, C.F. (1987) "The break-bulk role of terminals in many-to-many logistic networks", Operations Research 35(4): 543-555.

[8] Daganzo, C.F. (1988) "A comparison of in-vehicle and out-of-vehicle freight consolidation strategies", Transportation Research B 22B(3): 173-180. 
[9] Evers, P; Beier, F. (1998) "Operational aspects of inventory consolidation decision making", Journal of Business Logistics 19(1): 173-189.

[10] Hakimi, S.L. (1964) "Optimum locations of switching centers and the absolute centers and medians of a graph", Operation Research 12: 450-459.

[11] Hall, R.W. (1987) "Consolidation strategy: inventory, vehicles and terminals", Journal of Business Logistics: 57-73.

[12] Hall, R.W. (1987) "Direct versus terminal freight routing on networks with concave costs", Transportation Research B 21(4): 287-298.

[13] Hall, R.W. (1987) "Comparison of strategies for routing shipments through transportation terminals", Transportation Research A 21A(6): 421-429.

[14] Handler, G.; Mirchandani, P. (1979) Location on Networks Theory and Algorithms. The MIT Press Cambridge, London.

[15] Klincewicz, J.; Rosenwein, M.B. (1997) "Planing and consolidating shipments from a warehouse", Journal of the Operational Research Society 48: 241-246.

[16] Mahomud, M. (1992) "Optimal inventory consolidation schemes: a portfolio effect analysis", Journal of Business Logistics 13(1): 193-214.

[17] Min, H.; Cooper, M. (1990) "A comparative review of analytical studies on freight consolidation and backhauling", Logistics and Transportation Review 26(2): 149-169.

[18] Min, H. (1996) "Consolidation terminal location-allocation and consolidated routing problems", Journal of Business Logistics 17(2): 235-263.

[19] Mirchandani, P., Francis, R. (1990) Discrete Location Theory. Wiley-Interscience Series in Discrete Mathematics and Optimization, New York.

[20] Pooley J., Stenger A.J. (1992) "Modeling and evaluating shipment consolidation in a logistics system", Journal of Business Logistics 13(2): 153-174.

[21] Roundy, R. (1985) "98\% effective integer-ratio lot sizing for one-warehouse multiretailer systems", Management Science 31(11): 1416-1431.

[22] Lim, W.S.; Ou, J.; Teo, C.-P. (668) "Inventory cost effect of consolidating several one warehouse multiretailer systems", Operations Research 51(4): 668-672.

[23] http://129.219.27.161/Aerospace1_HT/default.aspx 